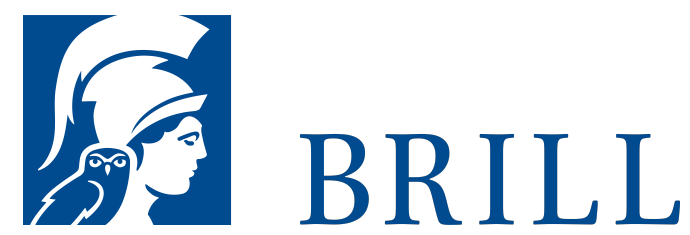

\title{
Die Bedeutung von „wissen“
}

\section{Eine Untersuchung zur Kontextabhängigkeit von}

Wissensaussagen

\section{Author: Erik Stei}

Wissen Sie, dass Sie gerade eine Buchzusammenfassung lesen? Falls Sie versucht sind, diese Frage zu bejahen: Wissen Sie, dass Sie gerade nicht träumen? Und falls sie das nicht wissen, wissen Sie dann auch nicht, dass sie gerade eine Buchzusammenfassung lesen? In der erkenntnistheoretischen Diskussion erfreuen sich Positionen großer Beliebtheit, die davon ausgehen, dass Antworten auf diese Fragen in gewisser Weise kontextabhängig sind. Es ist allerdings selbst unter Vertretern dieser Positionen strittig, wie sich diese Kontextabhängigkeit auswirkt. Es gibt konkurrierende Meinungen dazu, ob ein und dieselbe Wissensaussage in einem Kontext wahr, in einem anderen aber falsch sein kann, und dazu, wessen Kontext hierbei die entscheidende Rolle eingeräumt werden soll. Dieses Buch leistet einen darstellenden, einen kritischen und einen konstruktiven Beitrag zu dieser Debatte. Es führt in die Diskussion ein und analysiert die sprachphilosophischen und erkenntnistheoretischen Thesen des epistemischen Kontextualismus, Relativismus und Invariantismus. Die bestehenden Ansätze werden kritisch diskutiert und letztendlich verworfen, bevor eine eigenständige Variante der invariantistischen Theorie entwickelt wird.

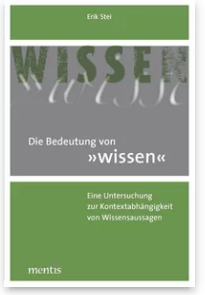

Pages: 349

Seiten

Language:

German

Subjects:

General,

Philosophy

Publisher: Brill | mentis

E-Book (PDF)

Released online: 24 Apr 2014

ISBN: $978-3^{-}$ 89785-644-8

List price

Paperback

Publication date: 24 Apr 2014 ISBN: 978-389785-843-5 List price 
For more information see brill.com

Order information: Order online at brill.com +44330 333 0049 | customerservices@brill.com Submission information: brill.com/authors

Titles published by Brill | Fink, Brill | mentis or Brill | Schöningh: +49(o)715413279216| brill@brocom.de 